\title{
Pattern of hearing loss among patients visiting ENT OPD at Janaki Medical College: A cross sectional study
}

\author{
Nabin Lageju* \\ Janaki Medical College Teaching Hospital \\ Ramdaiya, Janakpur
}

Assist. Professor, Department of ENT-Head and Neck Surgerv, Ianaki Medical College, Ianakpur

\section{ABSTRACT}

Background and Objectives: To study the pattern of hearing loss among patients visiting ENT OPD in Janaki medical college teaching hospital.

Material and Methods: The study was conducted in department of ENT- head and neck surgery in Janaki medical college teaching hospital from June to December 2016. All the clinically diagnosed cases with hearing impairment were enrolled in the study and hearing assessment done. Demographic data and PTA assessment were taken.

Results: Total of 119 patients were enrolled. Among them, male were 58(48.7\%) and female 61(51.3\%). In age distribution, commonly affected age group was 21-30 years followed by 31-40 years group.On comparing hearing level between both the ears, right ear was having mean hearing threshold of $45.4454 \mathrm{~dB}$ and left ear having $47.3277 \mathrm{~dB}$ with standard deviation 16.54665, 15.98363 respectively. The difference between both the values is statistically not significant ( $p$ value- 0.165 ). On evaluating type of hearing loss between both the ears, there were almost similar frequencies of hearing loss pattern ( $p$ value- 0.190).Out of 119 patients, 20(8.4\%) were having unilateral hearing loss. So total of 218(91.6\%) ears were affected out of 238 ears. Among them $116(48.8 \%)$ ears had conductive hearing loss, 30(12.6\%) ears had sensori-neural hearing loss and 48(20.2\%) ears had mixed hearing loss.On evaluating degree of hearing loss, patients were mostly having mild hearing loss $(41.2 \%)$ followed by severe hearing loss $(25.2 \%)$, moderate hearing loss $(24.4 \%)$. There was almost similar degree of hearing loss in both the ears with statistically insignificant ( $p$ value- 0.379 ).

Conclusion: Hearing impairment commonly involved female with younger population involvement. Hearing impairment was mostly conductive type. Hearing loss was mostly mild degree and bilateralism is common.

Key Words: Hearing impairment, PTA, Conductive, sensorineural, mixed

\section{INRODUCTION}

Hearing loss is one of the commonest morbidity affecting all age groups which can be congenital or acquired. It is the third leading chronic disability following arthritis and hypertension (1). Hearing loss can be conductive, sensorineural or mixed. Conductive hearing loss can be caused by tympanic membrane perforation, middle ear atelectasis, tympanosclerosis, ossicles destruction, and cholesteatoma. Infection and 
inflammation components transmit to the middle ear through round window cause cochlear destruction and sensorineural hearing loss (4). Sensorineural hearing loss is caused by diseases of cochlea or central auditory pathways. Hearing impairment is affecting nearly 250 million people in the world, and $75 \%$ of sufferers live in developing countries (2). Study by Little et al (3) showed around $16.6 \%$ of total population in Nepal, had hearing impairment. This study was conducted to see type of hearing loss with pattern and severity of hearing loss in mid central part of Nepal.

\section{MATERIALS AND METHODS}

The study was conducted in department of ENT- head and neck surgery in Janaki medical college teaching hospital from June to December, 2016. Patients visiting with hearing impairment were included in the study. Patients below 7 years were excluded from study. Informed consent was taken from all the patients. Written approval from institutional review board was taken. Demographic findings noted, examination done and advised for hearing assessment with pure tone audiometry. Hearing threshold was calculated from pure tone average of 4 frequencies $0.5,1,2$ and $4 \mathrm{KHz}$ for air conduction and bone conduction. SPSS 21 version used to evaluate the statistics. P value less than 0.05 was taken as level of significance.

\section{RESULTS}

Total of 119 patients were included in the study. Among them, 58 (48.74\%) were male and 61 (51.26\%) were females. In age distribution, commonly affected age group was 21-30 years followed by 31-40 years group (figure 1).

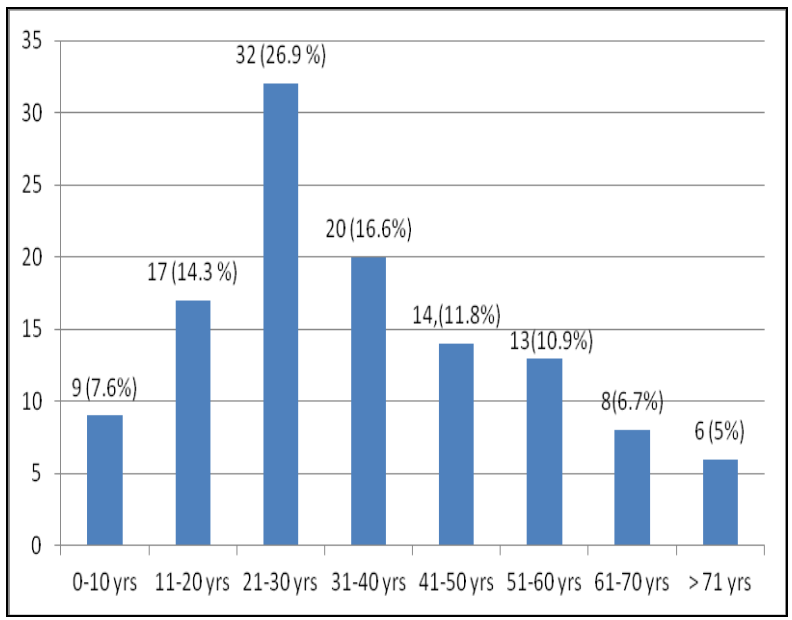

Figure 1: Age group distribution $(n=119)$

On comparing hearing level between both the ears, right ear was having mean hearing threshold of $45.445 \mathrm{~dB}$ and left ear having 47.33 dB with standard deviation 16.55, 15.98 respectively. The difference between both the values is statistically not significant ( $p$ value- 0.165). On evaluating type of hearing loss between both the ears, there were almost similar frequencies of hearing loss pattern ( $p$ value-0.190).

Table 1: Hearing threshold level $(n=119)$

\begin{tabular}{|l|l|l|}
\hline Hearing & Mean \pm SD & $\boldsymbol{p}$-value \\
\hline Right Ear Hearing & $45.45 \pm 16.55$ & \multirow{2}{*}{0.165} \\
\cline { 1 - 2 } Left Ear Hearing & $47.33 \pm 15.98$ & \\
\hline
\end{tabular}

Figure 2: Types of hearing loss in both the ears $(n=119)$

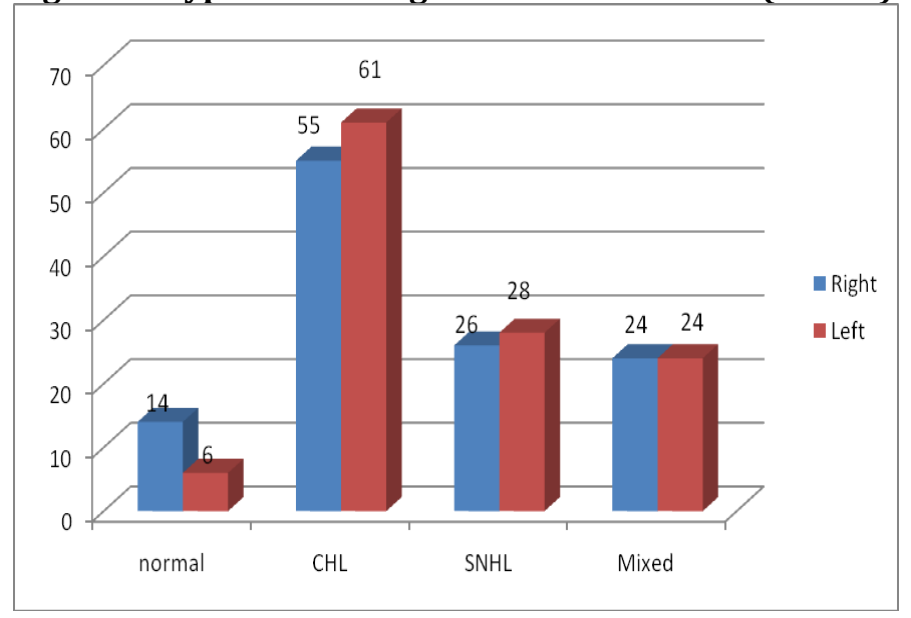


Out of 119 patients, 20 (8.4\%) were having unilateral hearing loss. So total of 218 (91.6\%) ears were affected out of 238ears. Among them 116 (48.8\%) ears had conductive hearing loss, 30 (12.6\%) ears had sensorineural hearing loss and 48 (20.2\%) ears had mixed hearing loss. There is clustering of CHL in younger age groups while SNHL and mixed hearing loss were seen in older age groups as shown in fig 3 and 4 .

On evaluating degree of hearing loss, patients

Figure 3: Distribution of hearing loss type in right ear with age group $(n=119)$

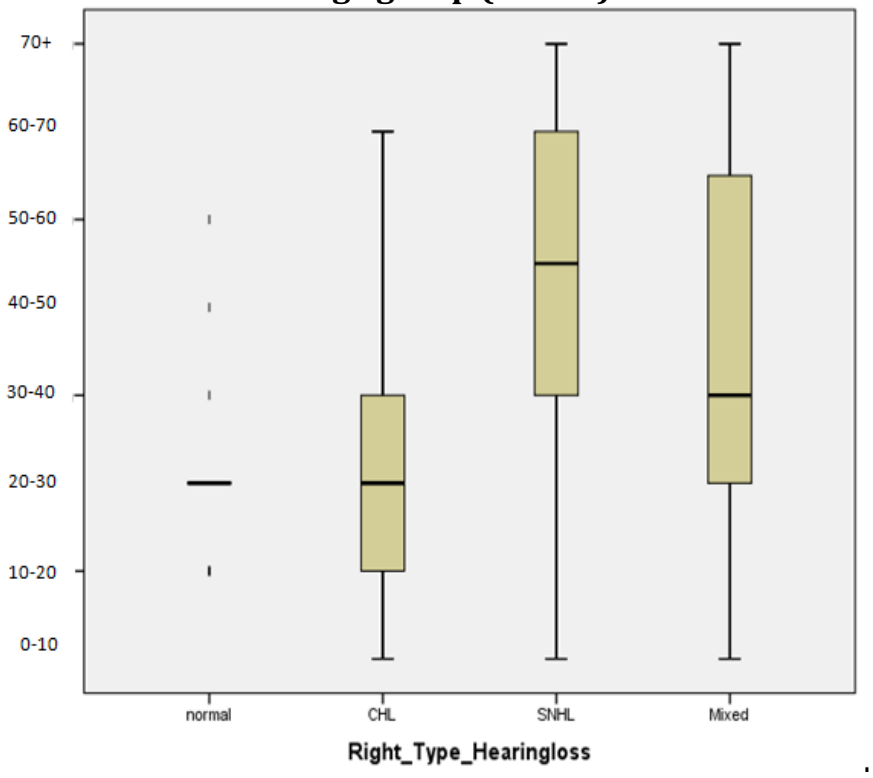

Figure 4: Distribution of hearing loss type in left ear with age group distribution

( $n=119)$

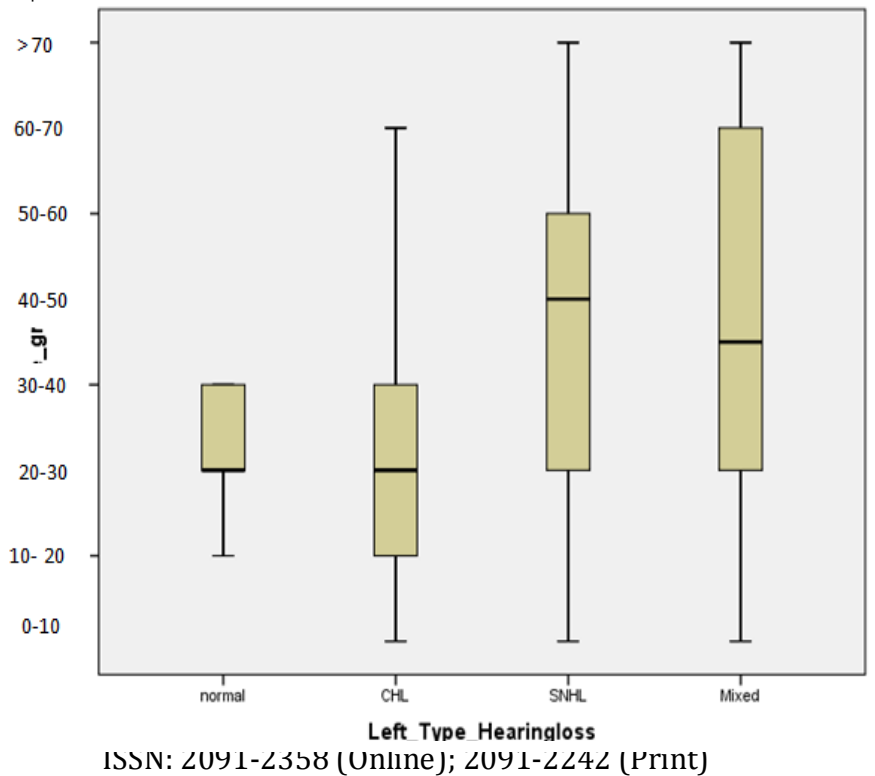

were mostly having mild hearing loss $(41.2 \%)$ followed by severe hearing loss (25.2\%), moderate hearing loss (24.4\%). There was almost similar degree of hearing loss in both the ears with statistically insignificant level ( $p$ value- 0.379 ) as shown in figure 5.

\section{DISCUSSION}

Hearing impairment is one of commonest morbidity affecting daily activities. It can be congenital or acquired. It is the public health problem in developing countries and even in developed countries.

In our study we studied 119 patients visiting with hearing impairment. Among them 99 patients were having bilateral hearing loss. Commonly affected age groups were 21-30yrs age group followed by 31-40yrs group. This result in accordance with study by Islam et al(5).

Among patients with hearing impairment conductive hearing loss (48.8\%) was most common followed by mixed (20.2\%) and sensorineural hearing loss(12.6\%) respectively. Study done in Tanzania showed more incidence of sensorineural hearing loss than conductive and mixed hearing loss(6). When studying incidence among male and female patients, female(51.3\%) were more affected than male(48.3\%).This result is in accordance with Olusesi et al's study(7). Other studies showed male more affected than female (8-12).There was clustering of cases with conductive hearing loss in younger age groups in 11-20, 21-30, 31-40 yrs age groups. But cases with sensorineural and mixed hearing loss evenly involved patients above 20-30 yrs age group. Patients were mostly having mild hearing loss followed by severe and moderate hearing loss. Study by Paul (13) showed most patients(68.3\%) had mild and moderate hearing loss. Less sample 
size was limitation of study and large sample size is required for better result.

\section{AUTHOR'S CONTRIBUTION:}

NL- Planning, Data collection, data analysis

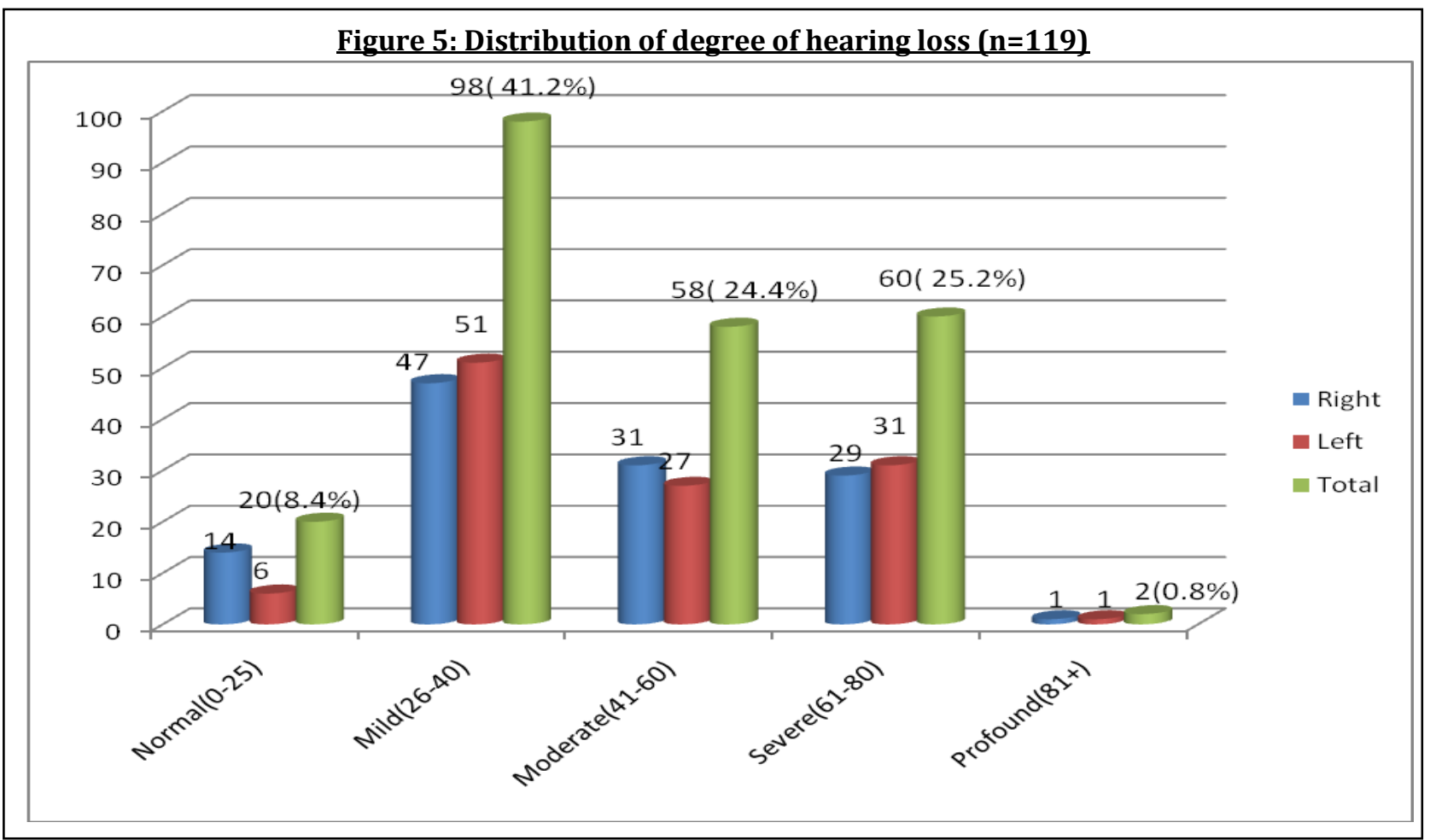

and final manuscript preparation.

\section{CONCLUSION}

From our study it can be concluded than hearing impairment commonly involved female with younger aged involvement. So, preventive measures should be targeted to younger population to curb chronic disability. Hearing impairment was mostly conductive followed by mixed and sensorineural hearing loss. Hearing loss was mostly mild degree and bilaterality is common.

\section{ACKNOWLEDGEMENT}

I would like to thank Mr. Ram Prakash Mahato for carrying out pure tone audiometry for all the patients. Also I would like to thank Dr. Niranjan K. Goit and Mr. Jai Kisun Yadav for helping and collecting data.
SOURCE OF SUPPORT: Janaki Medical College teaching Hospital, Janakpur, Nepal.

CONFLICT OF INTEREST: None declared.

\section{REFERENCES}

1. Collins JG. Prevalence of selected chronic conditions: United States, 1990-1992. Vital and health statistics Series 10, Data from the National Health Survey 1997(194):1-89.

2. Organization WH. Deafness and Hearing Impairment, Fact Sheet No. 300 Geneva. Switzerland: World Health Organization 2010.

3. Little P, Bridges A, Guragain R, Friedman D, Prasad R, Weir N. Hearing impairment and ear pathology in Nepal. J Laryngology \& Otology 1993;107(05):395-400. 
4.Ballenger JJ, Snow JB. Ballenger's otorhinolaryngology: head and neck surgery: PmphUSA; 2003.

5. Islam MA, Islam MS, Sattar MA, Ali MI. Prevalence and pattern of hearing loss. Medicine Today 2012;23(1):1821.

6. Mkumbo RE. Pattern of hearing impairment among patients with hearing loss attending at the Orl Department of Muhimbili National Hospital: Muhimbili University of Health and Allied Sci 2012.

7. Olusesi A. Sensorineural hearing loss in Lagos; study of aetiological and audiometric pattern [dissertation]. Lagos: National Postgraduate Medical Coll Nigeria 2002:30-53.

8. Sharma M, Singh P, Kapoor M, Goel M. Pattern of sensorineural hearing loss in patients attending ENT OPD. Int J Oral Health Med Res 2015;2:5-8.

9. Johansson MS, Arlinger SD. Prevalence of hearing impairment in a population in Sweden: Prevalencia de las pérdidas auditivas en una población de Suecia. Int J Audiol 2003;42(1):18-28.

10. Olusanya BO, Okolo A, Adeosun A. Predictors of hearing loss in school entrants in a developing country. J Postgraduate Med 2004;50(3):173.

11. Da Lily-Tariah 0, Ukoli C. Aetiological factors in acquired sensorineural hearing loss in Jos. Niger Med J 2003;44:4-6.

12. McPherson B, Holborow C. A study of deafness in West Africa: the Gambian hearing health project. Int J Pediatric Otorhinolaryngol 1985;10(2):115-35.

13. Adobamen PROC. The pattern of hearing loss as seen at the University of Benin Teaching Hospital, Benin City, Nigeria. Gomal J Med Sci 2014;11(2).

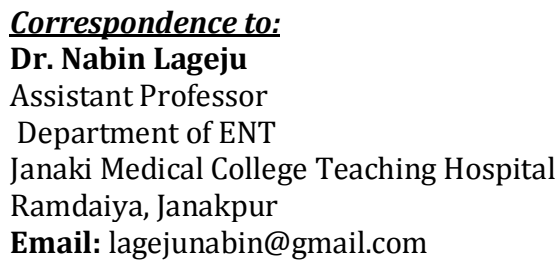

